\title{
Neurocognitive Disorders and HIV/AIDS: A Review of the Literature
}

\author{
Robert Mahamud Mussa ${ }^{1}$, Gilbert Lelo Mananga ${ }^{1}$, Désiré Katumbay Tshala ${ }^{1}$, \\ King Lovonga Toko², Nkodila Aliocha ${ }^{2,3^{*}}$ \\ ${ }^{1}$ Neuropsychopathological Center, University of Kinshasa, Kinshasa, Democratic Republic of the Congo \\ ${ }^{2}$ Faculty of Public Health, LOMO University Reseach, Kinshasa, Democratic Republic of the Congo \\ ${ }^{3}$ Faculty of Family Medicine, Protestant University of Congo, Kinshasa, Democratic Republic of the Congo \\ Email: *nkodilaaliocha@gmail.com
}

How to cite this paper: Mussa, R.M., Mananga, G.L., Tshala, D.K., Toko, K.L. and Aliocha, N. (2021) Neurocognitive Disorders and HIV/AIDS: A Review of the Literature. Open Access Library Journal, 8: e7308 https://doi.org/10.4236/oalib.1107308

Received: March 13, 2021

Accepted: April 22, 2021

Published: April 25, 2021

Copyright $\odot 2021$ by author(s) and Open Access Library Inc.

This work is licensed under the Creative Commons Attribution International License (CC BY 4.0).

http://creativecommons.org/licenses/by/4.0/ (c) (i) Open Access

\begin{abstract}
Background and aim: Since the discovery of ARVs, HIV/AIDS has become a chronic disease with the corollary of the aging of person living with HIV (PLHIV). This paradoxical aging is unfortunately accompanied by neurocognitive disorders (NCDs), which can be detected by the clinic and neuropsychological tests. The aim of this study is to assess the prevalence of NCDs before and after the era of antiretrovirals (ARVs). Methods: A retrospective study compared the prevalences of NCDs before and after the era of ARVs. Socio-demographic characteristics, stages of disease, prevalence of NCDs, and neurological and psychiatric disorders were the parameters of interest. Results: Age and sex: $34 \pm 9$ years, sex ratio $1 \mathrm{H}$ : $1 \mathrm{~F}$ versus $47.4 \pm 10.2$ years, sex ratio 3F: $1 \mathrm{H}$ Depression: $23 \%-29 \%$ at Stages I and II before ARVs NCDs: $11.4 \%$ (severe NCDs 8.7\%) (light NCDs $2.7 \%$ ) versus 75\% (66\% light NCDs, $8 \%$ moderate NCDs, $1 \%$ severe NCDs). Conclusion: The combination of the clinic and neuropsychological testing showed a clear progression of mild and moderate neurocognitive disorders in older and older, predominantly female PHAs, both asymptomatic and symptomatic on antiretroviral drugs.
\end{abstract}

\section{Subject Areas \\ HIV, Public Health}

\section{Keywords}

ARVs, NCDs, Neuropsychological Tests, Elderly PHAs, Predominantly Female 


\section{Introduction}

Neurocognitive disorders (NCDs) and aging of PLHIV on ARVs are well documented facts to date [1] [2]. Newer ARV treatments have reduced the frequency of severe forms of NCDs. However, the prevalence of mild forms remains high and is found even in cases of undetectable viral load [3]. This prevalence varies according to the studies, and asymptomatic NCDs can account for $60 \%$ of asymptomatic NCDs at all stages [4]. These disorders negatively interfere with daily activities, including treatment adherence, quality of life and life expectancy [5] [6] [7] [8]. Given the lack of trained personnel and the precariousness of hospital infrastructures, aging with HIV will be the future challenge of the pandemic in sub-Saharan Africa in the near future. The aim of the study is to review the literature on NCDs before and after the discovery of ARVs.

\section{Methods}

This retrospective study compiled the studies conducted on NCDs across the world from 1987 to 2017. Engines including google scholar, Medline, Home Pubmed, Home PMC and DMS/CDC/ONU/STDA, were used to organize scientific and factual information for NCDs. The parameters of interest were socio-economic characteristics, stage of disease and prevalence of neurocognitive disorders.

Data obtained from internet research were compiled and analyzed by presenting them as percentage, mean and standard deviation for each article included in this topical review.

\section{Results}

This review of the literature included 7 studies to show the impact of HIV on neurocognitive disorder. These are not the only articles that have studied this entity, but others are not included. The 7 most selected articles are produced in the DRC by the authors' teams to show that HIV/AIDS causes neurological damage that impacts the quality of life of PLHIVs.

1st study: HIV seroprevalence in a population of neuropsychiatric patients in Kinshasa, Zaire (1987) [9].

1) Sociodemographic characteristics (age and sex): mean age was 30 years with extremes ranging from 20 to 39 years and a sex ratio of $1 \mathrm{H}: 1 \mathrm{~F}$.

2) HIV seroprevalence in neurological and psychiatric patients: the highest HIV seroprevalence in neurological patients was found in patients with an expansive intracranial process versus depressed psychiatric patients (33\% vs $23 \%$ ). This first study did not demonstrate TNC.

2nd study: Neuropsychiatric manifestations of AIDS (1989) [10].

1) Socio-demographic characteristics: the mean age was 30 years with extremities ranging from 19 to 49 years and a sex ratio of $1 \mathrm{H}: 1 \mathrm{~F}$.

2) Clinical diagnoses: 
- Depressive syndrome: $29 \%$.

- Intracranial expansive process: $29 \%$.

- Meningeal syndrome: $18.4 \%$.

3) Clinical Stages:

- Pre-AIDS (I): $20.4 \%$.

- $\operatorname{AIDS}(\mathrm{II}): 79.6 \%$.

This second study did not highlight neurocognitive disorders but noted neuropsychiatric manifestations in the early stages of the disease.

3rd study: Neurological complications of HIV-Seropositive. Internal Medecine Impatients in Kinshasa, Zaire (1992) [11].

1) Sociodemographic characteristics: mean age was $34.3 \pm 9$ years with a sex ratio of $1 \mathrm{H}: 1 \mathrm{~F}$.

2) Clinical diagnoses:

- HIV associated dementia complex: $8.7 \%$.

- HIV associated minor cognitive/motor disorder: $2.7 \%$.

- HIV myelopathy: $1 \%$.

- Cryptococcal meningitis: 5.6\%.

- Mycobacterium avium meningitis: $2 \%$.

- Cerebral vascular accident: $4 \%$.

3) Clinical Stages:

- Stage 3: $48 \%$.

- Stage 4: $47 \%$.

This study, which associated an Alzheimer's disease questionnaire to the Clinic, revealed $11.4 \%$ of neurocognitive disorders in the final stage of the disease (III and IV) [11].

4th study: Syndromic profile of the neuropsychiatric manifestations of AIDS, Zaire, (1992) [12].

1) Socio-demographic characteristics: the mean age was 35.5 years with a sex ratio of $1 \mathrm{H}$ : $1 \mathrm{~F}$ but with a predominance of females (53.6\% vs $46.4 \%$ ).

2) Clinical Diagnostics :

- AIDS dementia complex: $4 \%$.

- Anxio-depressive state: $44.4 \%$.

This exclusively clinical study noted $4 \%$ of severe neurocognitive disorders among patients versus $44 \%$ of psychiatric manifestations. The clinical stage of the patients had not been mentioned.

5th study: WHO neuropsychiatricAIDS study. Cross-sectional phase II. Neuropsychological and neurological findings, (1994) [13].

1) Diagnosis/prevalence of CDT

a) Seroprevalence of symptomatic (+) HIV patients vs. HIV (-) patients:

- Munich $12 \%$ vs $1.2 \% \mathrm{p}<0.05$

- Bangkok $15.8 \%$ vs $3.4 \%$.

- Nairobi $15.3 \%$ vs $3.2 \%$ p $<0.5$.

- Sao Paolo $17 \%$ vs $3.9 \%$.

- Kinshasa $21.8 \%$ vs. $1.2 \%$. 
b) Seroprevalence of symptomatic HIV (+) vs. HIV (-) TNC patients:

- Kinshasa $21.8 \%$ vs $1.2 \% \mathrm{p}<0.5$.

This multicenter study, which used a battery of neuropsychological tests, showed a high frequency of CNTs in symptomatic and asymptomatic HIV patients with the same prevalence in developed and underdeveloped countries.

6th Study: HIV-1 Associated Cognitive and Motor Syndrome (1994) [14].

1) HIV-associated prevalence of moving:

- USA 65\% (1986).

- France $54.8 \%$ (1987).

- Tanzania 54\% (1989).

- RCA 3.3\% (1989).

- Burundi 46.6\% (1991).

- DRC 8.7\% (1992).

- USA 7.3\% (1992).

- UK $4 \%$ (1991).

- Netherlands 7.5\% (1993).

- India 6\% (1994).

2) Clinical Stages: II and IV

Cognitive impairment was present at all stages but more frequently at stages II and IV.

7th study: Evaluation of the quality of life of PLHA on ARVs in Kinshasa (2017) [5].

1) Socio-demographic characteristics: The mean age was $47.4 \pm 10.2$ years with a sex ratio of $3 \mathrm{~F}$ over $1 \mathrm{H}$.

2) Clinical parameters:

- TNC $75 \%$, of which $66 \%$ were mild, $8 \%$ moderate, and $1 \%$ severe.

This study carried out on patients on ARVs with a neuropsychological test showed a high prevalence of TNC in general (75\%) but with a very low prevalence of the severe form (1\%).

\section{Discussion}

\subsection{Age and Gender}

Studies conducted in the first decade of the disease put the age of patients around 30 years with a sex ratio of $1 \mathrm{H}$ to $1 \mathrm{~F}$. In fact, this pandemic concerned preferentially young people at the height of sexual activity [15]. Recent studies show an age around 50 years with a feminization of the infection with a sex ratio of $3 \mathrm{~F}$ on $1 \mathrm{H}$. This age is evidence of the increased life expectancy of PHAs due to ARVs making this infection a chronic disease. The feminization could be explained by the multiple partnerships of men and the extent of the vaginal mucous membrane which favors male-female transmission as well as the younger age of the woman at infection [16] [17]. This feminization deserves particular attention in view of the economic role assigned to women in Black Africa, but also in the vertical transmission of the infection [16]. 


\subsection{Neuropsychiatric Manifestations}

The classification of Bangui, categorized the psychiatric manifestations at the IV stages of the disease (16). The first studies of this series, carried out in a neuropsychiatric environment, revealed expansive intracranial processes, meningeal syndromes and depressive states [9] [10]. This could be explained by the lack of systematic use of brain scans, which could reveal cerebral toxoplasmosis, as well as the performance of lumbar punctures to reveal cryptococcal meningitis or tubercular mycobacterium; three of the most common opportunistic infections encountered in stage IV of HIV infection. The third study carried out in a general hospital and which had associated the clinic and a neuropsychological test adapted to Alzheimer's disease had revealed a rate of $11.4 \%$ TNC of which $8.7 \%$ was AIDS dementia complex. This rate was close to that of countries with end-stage indudtrials [18].

The 4th study carried out the same year in a neuroosychiatric setting found $4 \%$ AIDS dementia complex. This difference could be explained by the nature of these structures, the first being more frequent than the second, which is more specialized.

The 5th multicentric study, carried out in Europe, Asia, Africa and South America, found $22.3 \%$ of TNC in KINSHASA, i.e. 3 times more than the study carried out two years earlier, and $9.6 \%$ of which were TNC in asymptomatic patients. Beyond the variability in prevalence in these 4 continents that can be attributed to different types of studies and methods used to detect TNCs, this study had the particularity of finding TNCs in asymptomatic patients in Kinshasa. This study provided evidence of the precocity of TNCs in HIV/AIDS, contradicting Bangui's classification [18].

The sixth study [14], which compared the prevalence of several clinical and autopsy studies on motor and cognitive syndrome, confirmed its variability depending on the type of study, diagnostic criteria, investigative techniques, and geographical characteristics. It also revealed that this syndrome, which is much more frequent in the terminal stage, can be seen in the early stages of the disease [19].

The 7th study [5] carried out in specialized centers for the management of PLHA on ARVs was characterized by a very high prevalence of mild and moderate CDT in the early stages. This prevalence was also noted by Bumoko et al. [6].

\section{Conclusion}

NCDs are congeners to aging in PLHIV. This study showed that while their incidence and severity decreased with ARVs, their prevalence continued to increase with a combination of clinical and neuropsychological testing. These TNCs, which negatively impact treatment adherence, quality of life and life expectancy, should be sought in any HIV-positive subject, even if asymptomatic. Their determinants should be the subject of future studies. 


\section{Acknowledgements}

The authors are thankful all who participated in the study.

\section{Authors' Contributions}

MM, MLG and NA designed data for the study. TLK contributed to the data collection. TKD supervised the study. All authors have read and approved the final and revised version of the manuscript.

\section{Conflicts of Interest}

The authors declare no conflicts of interest regarding the publication of this paper.

\section{References}

[1] Lescure, F.X. and Moulignier, A. (2014) Troubles neurocognitifs associés à l'infection VIH. Journal des Anti-Infectieux, 16, 67-73.

[2] Bacchus, J. (1998) HIV and Older Adult. Journal Genrant Nursing, 24, 41-46.

[3] Saylor, D., Dickens, A.M., Sackder, N., et al. (2014) HIV Associated Neurocognitive Disorder Pathogenesis and Protects for Treatment. Nature Reviews Neurology, 11, 17-051-B-10.

[4] Kevin, V., Melani, M., Oury, C., et al. (2017) Evolution de la plateforme neuro-VIH d'un hôpital universitaire par les patients et les médecins traitants. Revue Médicale Suisse, 13, 782-786.

[5] Muilu, J., Mananga, L.G. and Mampunza, M.S. (2017) Evaluation de la qualité de vie des personnes vivant avec le VIH/SIDA: Sous antirétroviraux à Kinshasa. Edition Universitaires Européennes, Mauritius, 31.

[6] Bumoko, M.M., Mussa, M., Sombo, M.T., Itakala, B., Lelo, M., Bukasa, K., et al. (2016) Habileté cognitive et fonctionnement quotidien des sujets sous thérapies antirétrovirale de l'infection au VIH. Annals of African Medicine, 10, 2451.

[7] Dauchey, F.A., Amieva, H, Collin, C., et al. (2009) Troubles cognitifs chez les personnes infectées par le VIH. Prévalence et facteurs associés au sein de la cohorte ANDS Cos Agnitaine. Analyse intermédiaire Inserm U 897, COR VIH ISPED, Université Victor Segalen Bordeaux 2: CHU Bordeaux, France, 2007-2209.

[8] Lemogne, C., Cole, P., Consoli, S.M. and Limosin, F. (2018) Psychiatric de Liaison. Lavoisier, Paris, 436.

[9] N’Galy, B., Mann, J.M., Columbers, R.L., et al. (1987) Séroprévalence HIV au sein d'une population des patients neuropsychiatriques à Kinshasa, Zaire. Annales de la Société Belge de Médecine Tropicale, 67, 291-294.

[10] Mussa, M., Guy, D., Kazadi, K., et al. (1989) Les manifestations neuropsychiatriques du SIDA, Etude clinique à propos de 44 cas observés au CNPP/Mont-Amba à KinshasaAf. African Journal of Neurological Sciences, 8, 8-11.

[11] Perrieus, J.H., Mussa, M., Luabeya, M.K., Kayembe, K., Kapita, B., Brown, C., et al. (1992) Neurological Complications of HIV-1 Seropositive Internal Medicine Patients in Kinshasa Zaire. Journal of Acquired Immune Deficiency Syndromes, 5, 333-340.

[12] Luabeya, M.K., Tshiaka, K., Mussa, M. and Kayembe, N.T. (1994) Profil Syndromique des manifestations neuropsychiatriques du SIDA à Kinshasa/Zaire. African Journal 
of Neurological Sciences, 13, 17-19.

[13] Maj, M., Satz, P., Janssen, R., Zaudig, M., Starace, F., D’Elia, L., Sughondhabirom, B., et al. (1994) Who Neuropsychiatric AIDS Study: Cross Sectional Phase II. Neuropsychological and Neurological Findings. Archives of General Psychiatry, 51, 51-60. https://doi.org/10.1001/archpsyc.1994.03950010051007

[14] Mussa, M., Preux, P.M., Debrock, C., et al. (1997) Syndrome cognitif et mode associés au VIH. Cahier Santé, 7, 187-193.

[15] Swedish International Development Cooperation Agency (1998) Prévention et lutte. Sommet modial des ministres de la Santé sur les programmes et prévention du SIDA. Swedish International Development Cooperation Agency, Stockhlom, 6-7.

[16] Girard, P.M., Kadama, C.H. and Pialoux, G. (2004) VIH. Edition, 6ème Edition, Vol. 4, Girad, Malmaison, 5-11.

[17] Carter, M.W., Marie Kraft, J., Koppenhaver, T., Galavotti, C., Roels, T.H., Kilmarx, P.H. and Fidzani, B. (2007) "A Bull Cannot Be Contained in a Simple Kraal”: Concurrent Sexual Partnership in Botswana. AIDS and Behavior, 11, 822-839. https://doi.org/10.1007/s10461-006-9203-6

[18] Levy, M.R. and Bredesen, D.E. (1998) Central Nervous Dysfunction in Acquired Immunodeficiency Syndrome. Journal of Acquired Immune Deficiency Syndromes, 1, 41-64.

[19] Gray, F., Belec, L., Geny, C., et al. (1993) Diagnostic des encéphalopathies diffuses de l'adulte au cours de l'infection à Vih (1ère partie). Presse Médicale, 22, 1226-1231. 